\title{
Two New Cases of KIR3DP1, KIR2DL4-Negative Genotypes, One of which is also Lacking KIR3DL2
}

\author{
Wanda Niepiekło-Miniewska $\cdot$ Natalia Żuk • Joanna Dubis • Maciej Kurpisz • \\ David Senitzer • Anna Havrylyuk • Ryszard Grendziak • Wojciech Witkiewicz • \\ Valentyna Chopyak • Piotr Kuśnierczyk
}

Received: 13 January 2014/ Accepted: 29 April 2014/Published online: 18 July 2014

(C) The Author(s) 2014. This article is published with open access at Springerlink.com

\begin{abstract}
The killer immunoglobulin-like receptor $(K I R)$ genes KIR2DL4, KIR3DL2, and KIR3DP1 are present in virtually all humans. KIR2DL4 encodes a receptor present on uterine and decidual natural killer (NK) cells and some peripheral blood NK cells. Its only known ligand is the human leukocyte antigen-G molecule expressed on extravillous trophoblasts, and on tissues in some diseases. KIR3DL2 binds HLA-A*03 and HLA-A*11 as well as HLA-B*27 dimers, and microbial CpG DNA. KIR3DP1 is a pseudogene. During our immunogenetic studies we found two individuals, one from Lower Silesia district in Poland, and another from Western Ukraine, who were reproducibly negative for KIR2DLA and KIR3DP1 genes, using three
\end{abstract}

W. Niepiekło-Miniewska · P. Kuśnierczyk ( $\square)$

Laboratory of Immunogenetics and Tissue Immunology,

Department of Clinical Immunology, Ludwik Hirszfeld Institute of Immunology and Experimental Therapy, Polish Academy of Sciences, Rudolfa Weigla 12, 53-114 Wrocław, Poland

e-mail: pkusnier@iitd.pan.wroc.pl

N. Żuk · J. Dubis · W. Witkiewicz · P. Kuśnierczyk Research and Development Centre, Regional Specialised Hospital, Wrocław, Poland

M. Kurpisz

Department of Reproductive Biology and Stem Cells, Institute of Human Genetics, Polish Academy of Sciences, Poznań, Poland

D. Senitzer

City of Hope Comprehensive Cancer Center, Duarte, CA, USA

A. Havrylyuk · V. Chopyak

Department of Clinical Immunology and Allergology, Danylo

Halytsky Lviv National Medical University, Lviv, Ukraine

R. Grendziak · W. Witkiewicz

Department of Vascular Surgery, Regional Specialised Hospital,

Wrocław, Poland different PCR systems. Both individuals displayed very similar genotypes, possessing only KIR3DL3, KIR2DL3, KIR2DP1, KIR2DS1, and probably a rare variant of KIR2DL1. The Pole had also KIR3DL2, which the Ukrainian was apparently lacking. The Lower Silesia has been populated after the Second World War by a remarkable percentage with displaced people from Western Ukraine, which might contribute to genetic similarity of the two individuals described here.

Keywords Killer cell immunoglobulin-like receptor . Framework genes · Deletion

\section{Introduction}

Killer cell immunoglobulin-like receptors (KIRs) are present on natural killer (NK) cells and some subpopulations of $\mathrm{T}$ lymphocytes. They have either inhibitory (long cytoplasmic tail-receptors KIR2DL and KIR3DL possessing two or three extracellular immunoglobulin-like domains, respectively) or activating (short cytoplasmic tail-receptors KIR2DS or KIR3DS) properties upon binding a ligand. Genes for majority of KIRs are not present in all individuals but only in a fraction of them (haplotypic polymorphism). However, some, so called framework genes, namely KIR3DL3, KIR $3 D P 1$, $K I R 2 D L 4$, and KIR3DL2, are present in virtually all genotypes (Jiang et al. 2012). Among these, KIR2DL4 gene has special properties: it codes for structural features characteristic for both inhibitory and activating KIR; it is expressed in all NK cells whereas other KIRs are rather distributed clonally on some NK cells; and in contrast to other KIRs which function as cell surface receptors, it is localized, in resting NK cells, in endosomes where it may bind its ligand, a soluble HLA-G molecule (Rajagopalan and Long 2012), although 
this view has been recently challenged (Le Page et al. 2014). KIR2DL4 molecule appears as a cell surface receptor on uterine and decidual NK cells and some (mostly activated) peripheral blood NK cells (Goodridge et al. 2009; Hromadnikova et al. 2013; Yan et al. 2007). KIR3DL2 binds HLA$\mathrm{A} * 03$ and HLA-A*11 as well as HLA-B*27 dimers, and also a microbial CpG DNA (Shaw and Kollnberger 2012; Sivori et al. 2010). KIR3DP1 is a pseudogene (Jiang et al. 2012). Here, we describe two cases of KIR2DL4-negative individuals detected in the Polish and Ukrainian populations. Both individuals present similar deletion of not only KIR2DL4 but also neighboring KIR genes, including KIR $3 D P I$. Interestingly, the Ukrainian individual was also lacking another framework gene, KIR3DL2.

\section{Materials and Methods}

\section{Study Subjects}

The study was approved by the Local Ethical Committee at the Research and Development Centre, Regional
Specialised Hospital, Wrocław, the Bioethics Committee of the Medical University of Poznań, and the Bioethics Committee of the Danylo Halytsky Lviv National Medical University.

No. 89 a 69 -year-old Polish male, $82 \mathrm{~kg}$ body weight, $171 \mathrm{~cm}$ high, body mass index (BMI) of 28.04, with arterial hypertension, morbus ischemicus cordis and aspirin idiosyncrazy but otherwise healthy and without genetic diseases in family.

No. $175 \mathrm{~K}$ a 67-year-old Polish male, $90 \mathrm{~kg}$ body weight, $177 \mathrm{~cm}$ high, BMI of 28.73, with total cholesterol and glucose at upper border of the norm, atherosclerosis, polycystic kidney disease, varices, nosebleed, and osteoporosis.

No. 24 a 22-year-old healthy male from western Ukraine, HIV-, HBV- and HCV-negative blood donor, recruited to a control group for our study on cryptorchidism (Kurpisz et al. 2011).

No. 58 a 19-year-old healthy male from western Ukraine, HIV-, HBV- and HCV-negative blood donor, recruited to a control group for our study on cryptorchidism (Kurpisz et al. 2011).
No.58
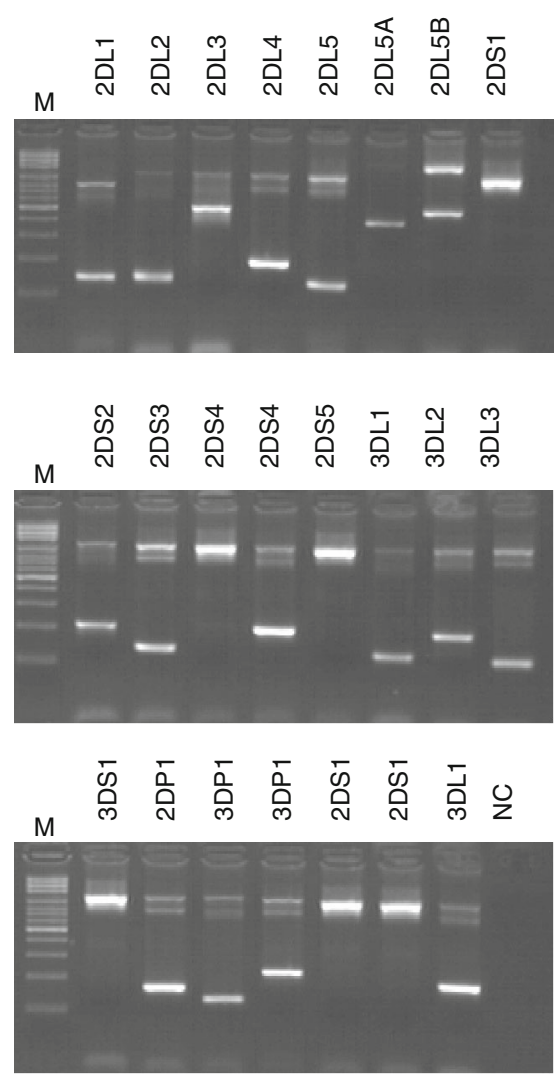

No.24
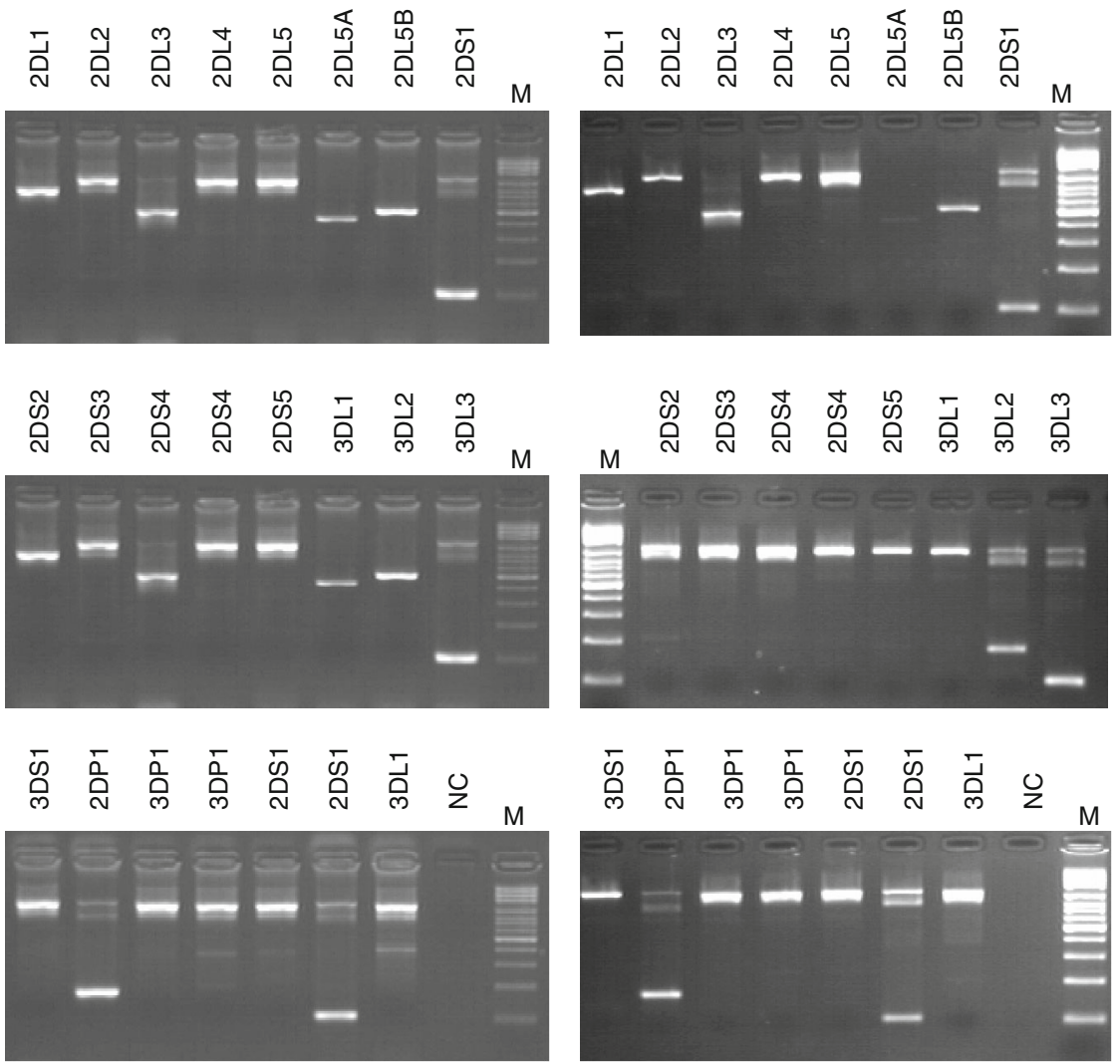

Fig. 1 Results of KIR typing using Olerup KIR Genotyping kit ${ }^{\mathrm{TM}}$. Interpretation of all results is shown in Table 1 and described in the text. M: marker of the molecular mass; NC: negative control. Polish individual No. 89 K; Ukrainian individual No. 24; Ukrainian individual No. 58 


\section{DNA Isolation}

Genomic DNA was isolated from venous blood using QIAamp DNA Blood Mini Kit Qiagen (Qiagen GmbH, Hilden, Germany), according to manufacturer's recommendations. DNA concentration was measured in NanoDrop 2000 UVVis Spectrophotometer (Thermo Scientific, NanoDrop Products, Wilmington, Delaware, USA).

\section{KIR Typing}

Three PCR-sequence-specific primers (SSP) systems were used

(a) Olerup SSP KIR Genotyping kit (Olerup GmbH, Vienna, Austria), lot No. $07 \mathrm{~N}$ including Taq polymerase. PCR-SSP procedure was performed according to manufacturer's instruction.

(b) SSP as described by Vilches et al. (2007) that enable to amplify short DNA fragments (96-158 bp), in our modification (Niepieklo-Miniewska et al. 2013)

(c) Multiplex PCR-SSP (four PCR reactions containing primers for 3-4 KIR genes each) as published earlier (Nowak et al. 2011; Sun et al. 2004).
Our KIR typing has been validated three times per year by the International KIR Exchange program organized by the Immunogenetics Center of the University of California at Los Angeles.

\section{Results}

Upon genomic KIR typing using commercial Olerup kit (see Materials and Methods) in disease association studies on Polish and Ukrainian patients and respective control groups, we noticed a lack of KIR2DL4 gene in one Polish (No. 89 K) and one Ukrainian (No. 24) control individual (Fig. 1). All other samples from both control and patient groups were positive (Fig. 1). The individual No. 24 apparently was lacking another framework gene, KIR3DL2, whereas another Ukrainian control individual, No. 58, possessed both genes (Fig. 1). To confirm this result, we repeated KIR typing using Olerup kit once more, with the same result (data not shown, and see Table 1). Furthermore, we checked the presence of KIR2DLA and KIR3DL2 genes in these samples using primers published by Vilches et al. (2007) (Fig. 2). Finally, we typed these samples again
Table 1 Summary of the results of testing individuals No. 89 K, No. 24 and No. 58 with Olerup PCR-SSP kit shown in Fig. 1 and second testing with identical results

Framework genes not detected in described individuals are show in bold

\begin{tabular}{|c|c|c|c|c|c|c|}
\hline $\begin{array}{l}\text { Primer } \\
\operatorname{mix}\end{array}$ & $\begin{array}{l}\text { Size of specific } \\
\text { PCR product (bp) }\end{array}$ & $\begin{array}{l}\text { Size of control } \\
\text { band (bp) }\end{array}$ & KIR gene & No. $89 \mathrm{~K}$ & No. 24 & No. 58 \\
\hline 1 & 145 & 800 & 2DL1 & - & - & + \\
\hline 2 & 145 & 1070 & 2DL2 & - & - & + \\
\hline 3 & 520 & 1070 & 2DL3 & + & + & + \\
\hline 4 & 200 & 1070 & 2DL4 & - & - & + \\
\hline 5 & 155 & 1070 & 2DL5A, 2DL5B & - & - & + \\
\hline 6 & 1650 & 430 & 2DL5A & - & - & - \\
\hline 7 & 1650 & 515 & 2DL5B & - & - & + \\
\hline 8 & 100 & 1070 & 2DS1 & + & + & - \\
\hline 9 & 205 & 1070 & 2DS2 & - & - & + \\
\hline 10 & 160 & 1070 & $2 \mathrm{DS} 3$ & - & - & + \\
\hline 11 & 215 & 1070 & 2DS4 & - & - & - \\
\hline 12 & 200 & 1070 & 2DS4 & - & - & + \\
\hline 13 & 110 & 1070 & 2DS5 & - & - & - \\
\hline 14 & 130 & 1070 & 3DL1 & - & - & + \\
\hline 15 & 95 & 1070 & 3DL2 & + & - & + \\
\hline 16 & 115 & 1070 & 3DL3 & + & + & + \\
\hline 17 & 130 & 1070 & $3 \mathrm{DS} 1$ & - & - & - \\
\hline 18 & 165 & 1070 & 2DP1 & + & + & + \\
\hline 19 & 125 & 1070 & 3DP1 & - & - & + \\
\hline 20 & 235 & 1070 & 3DP1 & - & - & + \\
\hline 21 & 145 & 1070 & $2 \mathrm{DS} 1 * 001$ & - & - & - \\
\hline 22 & 95 & 1070 & $2 \mathrm{DS} 1 * 002-008$ & + & + & - \\
\hline 23 & 80 & 1070 & $\begin{array}{l}\text { 3DL1*00401-00403, 019, } \\
\quad 021,036,037,039,056,072\end{array}$ & - & - & + \\
\hline 24 & - & - & Negative control & & & \\
\hline
\end{tabular}


with the use of multiplex PCR-SSP described previously (Sun et al. 2004) (Fig. 3). Our individuals No. $89 \mathrm{~K}$ and No. 24 were reproducibly KIR2DL4-negative in all these tests, in contrast to other individuals who were all positive (Fig. 1, 2, 3, and results not shown). They also lacked KIR3DPl which is present whenever KIR2DLA is present, with extremely rare exceptions (Jiang et al. 2012). They possessed KIR3DL3, 2DL3, 2DPI, and 2DSI, and No. $89 \mathrm{~K}$ had also KIR $3 D L 2$, absent from No. 24 genotype. Their genotypes contained KIR2DL3 gene, characteristic for the centromeric segment of the KIR region, but another centromeric gene, KIR2DL1, gave inconsistent results: it was detected by multiplex test (Fig. 3; Table 2) but neither by commercial test (Fig. 1; Table 1) nor by PCR-SSP using primers described by Vilches et al. (2007) (Fig. 2).
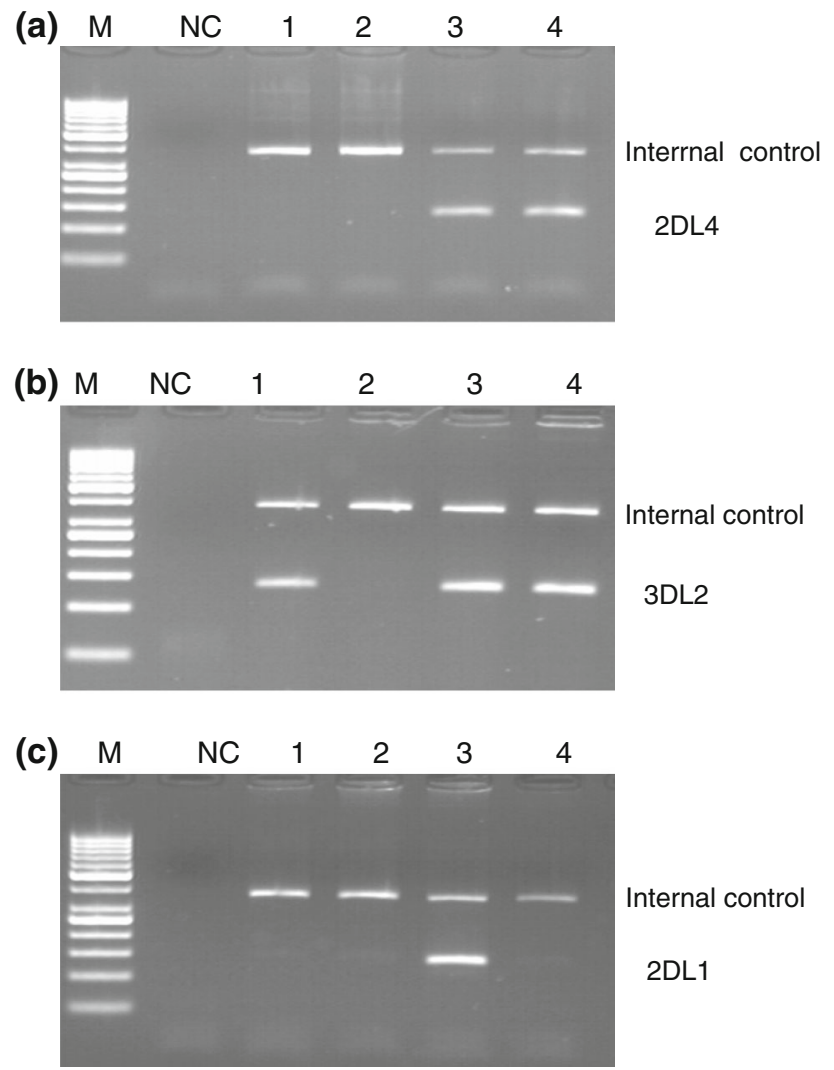

Fig. 2 Results of KIR typing using primers and PCR conditions described by Vilches et al. (2007). a KIR2DL4 typing of samples No. 89 K, No. 24 and two unrelated KIR2DL4-positive individuals. Both No. $89 \mathrm{~K}$ (lane 1) and No. 24 (lane 2) were negative (only internal control gave a product), whereas both positive control samples (lanes 3 and 4) gave KIR2DL4 amplicons. b KIR3DL2 typing of the same samples. Only sample No. 24 (lane 2) was negative for framework gene KIR $3 D L 2$, whereas both sample No. $89 \mathrm{~K}$ (lane 1) and unrelated positive control samples (lanes 3 and 4 ) gave positive reactions. c KIR2DL1 typing of the same samples. Only control sample shown in lane 3 was positive, whereas all other samples gave no product

\section{Discussion}

We have detected two KIR3DP1, KIR2DL4-negative individuals, one of which was also negative for the third framework gene, KIR3DL2. Such genotypes are extremely rare in world populations (Djulejic et al. 2010; Ewerton et al. 2007; Gomez-Lozano et al. 2003; Gonzalez-Galarza et al. 2011; Karlsen et al. 2007; Norman et al. 2002; Nowak et al. 2011; Ozturk et al. 2012; Taniguchi and Kawabata 2009; Traherne et al. 2010; Velickovic et al. 2006), and even haplotypes contributing to them, most frequently in heterozygotic configuration, are very rare (Gonzalez-Galarza et al. 2011; Jiang et al. 2012; Pyo et al. 2010; 2013; Traherne et al. 2010). We found in the www. allelefrequencies.net database (Gonzalez-Galarza et al. 2011) only ten KIR2DL4-negative genotypes in addition to two new ones described here (Fig. 4a), three KIR3DL2negative genotypes plus our Ukrainian (Fig. $4 \mathrm{~b}$ ), and six KIR3DPl-negative genotypes plus two described here (Fig. 4c) out of nearly 13,000 individuals tested worldwide (Gonzalez-Galarza et al. 2011). This speaks in favor of a strong positive selection for all three genes, including KIR3DP1. This pseudogene might be suspected to be preserved simply due to its close proximity to KIR $2 D L 4$ which is likely strongly selected for. However, KIR $3 D P 1$ is located on centromeric segment of KIR locus, whereas KIR2DL4 is on telomeric segment (Jiang et al. 2012; Pyo et al. 2013) which seems to exclude the close localization as a reason for preservation of KIR3DPI together with KIR2DL4. Nevertheless, genotypes containing KIR2DL4, but not KIR3DPl, are extremely rare, as only few such genotypes from Cook, Samoa, Tokelau, and Tonga Islands as well as from Turkey have been described so far (Velickovic et al. 2006) (Fig. 4c), and opposite configuration, $K I R 3 D P 1^{+}, K I R 2 D L 4^{-}$, was found in only single individuals from South Turkey, Brazil, and Bulgaria (Fig. 4a). Homozygous KIR $3 D L 2$ deletion is also very infrequent, as only three such cases exist in the database (GonzalezGalarza et al. 2011) and our Ukrainian No. 24 is the fourth one (Fig. 4b). Haplotypes with this deletion, but not in homozygous configuration, have been identified in some individuals by gene copy number detection (Pyo et al. 2013). The KIR3DL2 molecule plays an important role in both innate and adaptive immunity. It is expressed on NK cells, as well as on subpopulation(s) of $\mathrm{T}$ lymphocytes (Bowness et al. 2011; Wong-Baeza et al. 2013). It binds not only HLA-A*03 and HLA-A*11 heterotrimers as well as HLA-B*27 homodimers, but also microbial CpG DNA (Shaw and Kollnberger 2012; Sivori et al. 2010). It has the highest number of alleles, except for KIR3DL1/S1. This is suggestive of a strong selection for polymorphism (Shaw and Kollnberger 2012). 
Multiplex

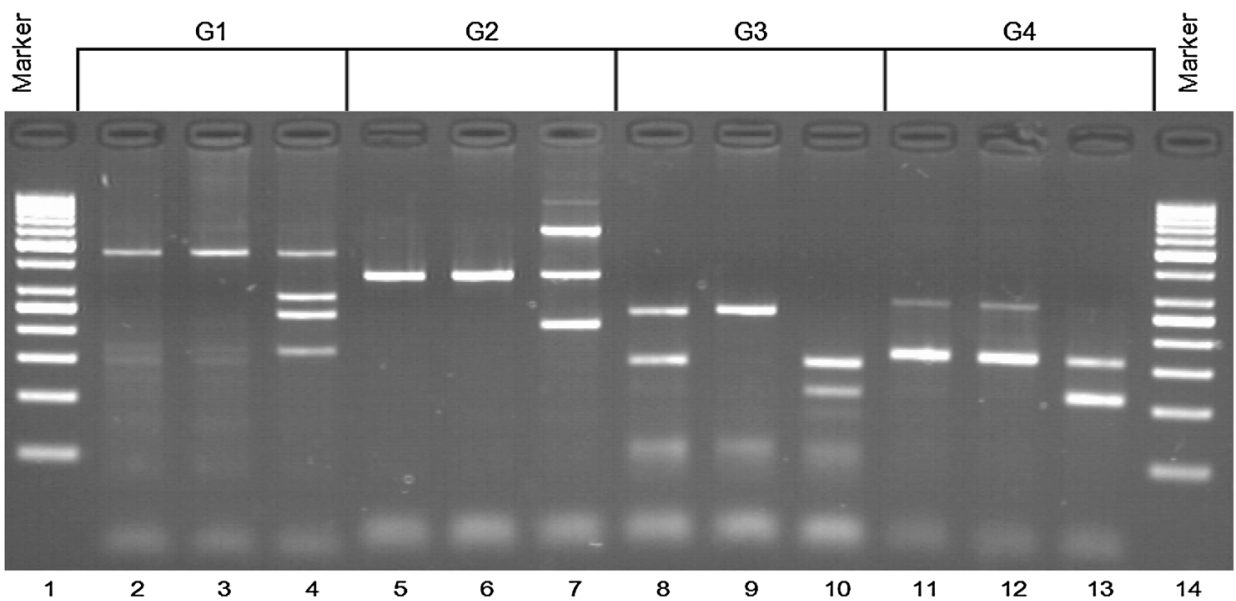

Fig. 3 Results of KIR typing using multiplex PCR-SSP kit (Sun et al. 2004). Samples No. 89 K (lanes 2, 5, 8 and 11), No. 24 (lanes 3, 6, 9 and 12) and framework gene-positive control sample No. $175 \mathrm{~K}$ (lanes 4, 7 , 10 and 13) were tested for the presence of particular KIR gene groups as shown, together with results, in Table 2. Please note the absence of

Table 2 Interpretation of results of multiplex PCR-SSP KIR typing shown in Fig. 3

\begin{tabular}{|c|c|c|c|c|c|}
\hline Multiplex group & KIR gene & Amplicon (bp) & $89 \mathrm{~K}$ & 24 & $175 \mathrm{~K}$ \\
\hline \multirow[t]{4}{*}{1} & 2DL1 & 437 & + & + & + \\
\hline & 2DS3 & 279 & - & - & + \\
\hline & 2DL4 & 232 & - & - & + \\
\hline & 2DL2 & 164 & - & - & + \\
\hline \multirow[t]{4}{*}{2} & 3DL1 & 565 & - & - & + \\
\hline & 2DL3 & 334 & + & + & + \\
\hline & $2 \mathrm{DS} 2$ & 204 & - & - & + \\
\hline & 3DS1 & 171 & - & - & - \\
\hline \multirow[t]{3}{*}{3} & 2DS1 & 231 & + & + & - \\
\hline & 3DL2 & 142 & + & - & + \\
\hline & 2DL5 & 113 & - & - & + \\
\hline \multirow[t]{4}{*}{4} & 2DS5 & 194 & - & - & - \\
\hline & 3DL3 & 155 & + & + & + \\
\hline & 2DS4n & 130 & - & - & - \\
\hline & 2DS4d & 108 & - & - & + \\
\hline
\end{tabular}

Framework genes not detected in described individuals are show in bold

In some very rare American haplotypes, most of the KIR3DL2 gene (intron 3 to beyond exon 9) was deleted, giving a typing pattern identical to our No. 24. Such a haplotype has also been detected in an American of Ukrainian descent, in addition in homozygous configuration (Traherne et al. 2010).

Interestingly, Lower Silesia was populated in remarkable fraction, after the Second World War, by people resettled from Western Ukraine. Therefore, not only No. 24
KIR2DL4 (G1) in samples No. $89 \mathrm{~K}$ and 24, and absence of KIR3DL2 (G3) in sample No. 24. KIR2DL1 (G1) gave clearly positive band in samples No. $89 \mathrm{~K}$ and 24 in this test, in contrast to negative results of these samples with both Olerup (Fig. 1) and Vilches et al. (2007) (Fig. 2) primers. Summary of these results is given in Table 2

but also No. $89 \mathrm{~K}$ genotype may be derived from there, whence similarity between these genotypes and with haplotypes described in the USA and mentioned above. It has been established by sequencing that all American KIR $3 D L 2$ deletion haplotypes contained exons 1-3 from KIR $3 D L 2 * 007$ allele, suggesting a recent common origin. It would be desirable then to check whether our genotypes No. $89 \mathrm{~K}$ and No. 24 bear the same allele that may be derived from the same recombination event.

We had a problem with establishing whether KIR2DL1 gene is present in our genotypes No. $89 \mathrm{~K}$ and No. 24. The reagents from both Olerup and Vilches et al. (2007) PCRSSP gave reproducibly negative results, whereas in the multiplex assay both individuals were clearly positive (Figs. 1, 2, 3; Tables 1, 2). It is likely that both our individuals possess genotypes similar to the haplotypes described earlier in Northern American Caucasian population (Pyo et al. 2013; Traherne et al. 2010) which contained a KIR2DL1/KIR2DS1 hybrid resulting from recombination event which deleted all KIR genes located between these two genes. This may explain why some PCRs detected KIR2DL1 in our samples, but other did not.

In conclusion, we found in our Slavic populations (Polish and Ukrainian), two individuals lacking several framework KIR genes, KIR3DP1, and KIR2DL4, and apparently also KIR2DL1. One of them was also negative for KIR3DL2. Both these individuals were relatively healthy in spite of very limited KIR gene repertoire. However, such genotypes are extremely rare in world populations. Therefore, studies on much larger populations 
(a)

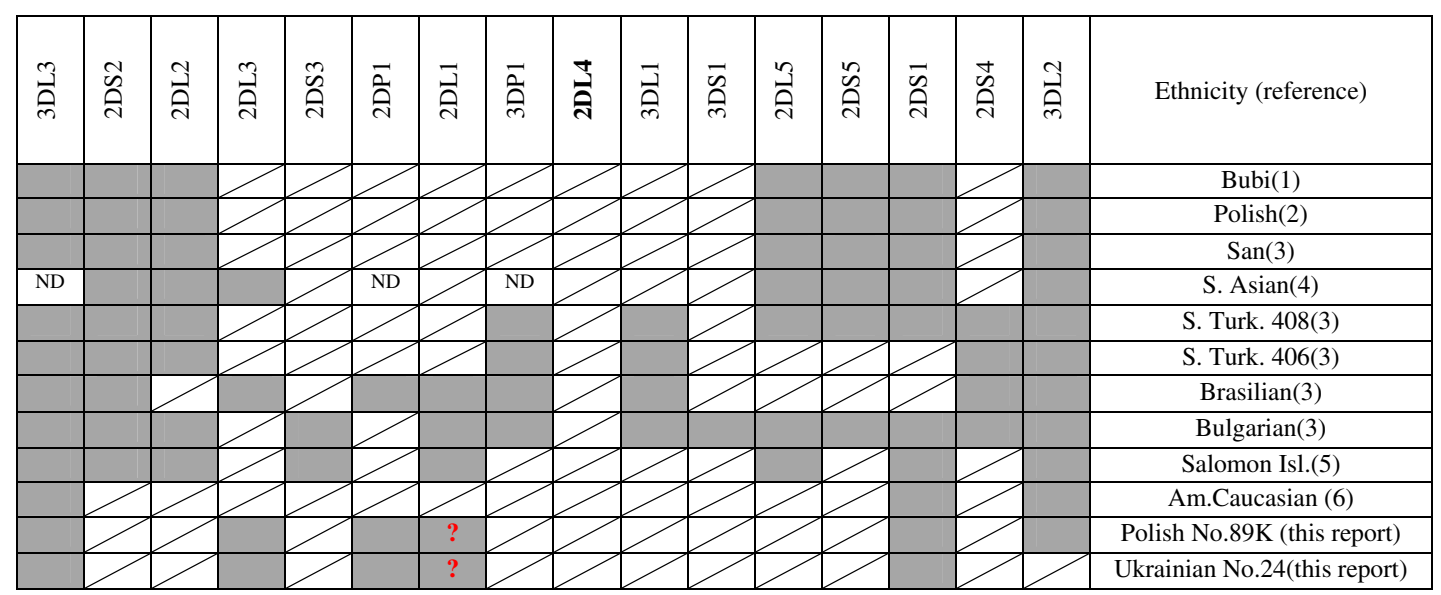

(b)

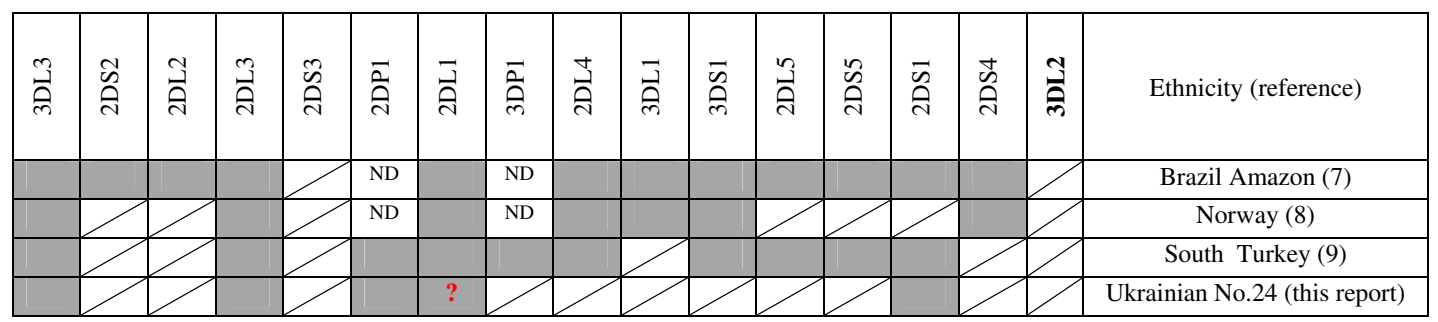

(c)

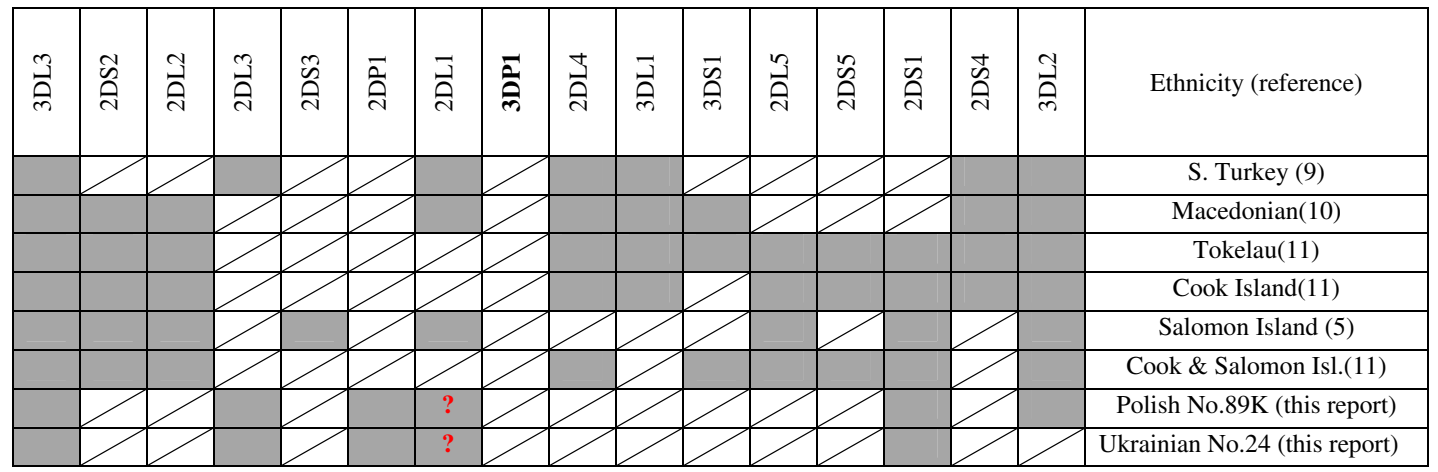

Fig. $4 K I R$ genotypes of published framework KIR-negative individuals. a KIR2DL4-negative individuals. Gray shadowed cells gene present, white diagonally crossed cells gene absent, question mark gene presence dubious (inconsistent results), $N D$ not done. b KIR genotypes of published KIR3DL2-negative individuals. Designations of cells as in Fig. 4a. c KIR genotypes of published KIR3DPI-

would be required to determine the effect(s) of these deletions on the health of such individuals.

Acknowledgments The research described in this paper was supported by two projects: WROVASC- "Integrated Centre of Cardiovascular Medicine" co-founded by the European Fund of Regional Development and national budget (the Innovative Economy Operational Program 2007-2013 1-1), and a grant from the Polish Ministry of Science and Higher Education No. NN407193439.

Open Access This article is distributed under the terms of the Creative Commons Attribution License which permits any use, distribution, and reproduction in any medium, provided the original author(s) and the source are credited. negative individuals. Designations of cells as in Fig. 4a. References: 1 Gomez-Lozano et al. 2003, 2 Nowak et al. 2011, 3 Gonzalez-Galarza et al. 2011, 4 Norman et al. 2002, 5 Taniguchi and Kawabata 2009, 6

Traherne et al. 2010, 7 Ewerton et al. 2007, 8 Karlsen et al. 20079 Ozturk et al. 201210 Djulejic et al. 2010, 11 Velickovic et al. 2006

\section{References}

Bowness P, Ridley A, Shaw J et al (2011) Th17 cells expressing KIR3DL2 + and responsive to HLA-B27 homodimers are increased in ankylosing spondylitis. J Immunol 186:2672-2680

Djulejic E, Petlichkovski A, Trajkov D et al (2010) Distribution of killer cell immunoglobulinlike receptors in the Macedonian population. Hum Immunol 71:281-288

Ewerton PD, Leite Mde M, Magalhaes M et al (2007) Amazonian Amerindians exhibit high variability of KIR profiles. Immunogenetics 59:625-630

Gomez-Lozano N, de Pablo R, Puente S et al (2003) Recognition of HLA-G by the NK cell receptor KIR2DL4 is not essential for human reproduction. Eur J Immunol 33:639-644 
Gonzalez-Galarza FF, Christmas S, Middleton D et al (2011) Allele frequency net: a database and online repository for immune gene frequencies in worldwide populations. Nucleic Acids Res 39(Database issue):D913-D919

Goodridge JP, Lathbury LJ, John E et al (2009) The genotype of the NK receptor, KIR2DL4, influences IFNgamma secretion by decidual natural killer cells. Mol Hum Reprod 15:489-497

Hromadnikova I, Pirkova P, Sedlackova L (2013) Influence of in vitro IL-2 or IL-15 alone or in combination with Hsp-70-derived 14-mer peptide (TKD) on the expression of NK cell activatory and inhibitory receptors. Mediators Inflamm 2013:405295

Jiang W, Johnson C, Jayaraman J et al (2012) Copy number variation leads to considerable diversity for B but not A haplotypes of the human KIR genes encoding NK cell receptors. Genome Res 22:1845-1854

Karlsen TH, Boberg KM, Olsson M et al (2007) Particular genetic variants of ligands for natural killer cell receptors may contribute to the HLA associated risk of primary sclerosing cholangitis. J Hepatol 46:899-906

Kurpisz M, Nakonechnyy A, Niepieklo-Miniewska W et al (2011) Weak association of anti-sperm antibodies and strong association of familial cryptorchidism/infertility with HLA-DRB1 polymorphisms in prepubertal Ukrainian boys. Reprod Biol Endocrinol 9:129

Le Page MEL, Goodridge JP, John E et al (2014) Killer Ig-like receptor 2DL4 does not mediatte NK cell IFG- $\gamma$ responses to soluble HLA-G preparations. J Immunol 192:732-740

Niepieklo-Miniewska W, Majorczyk E, Matusiak L et al (2013) Protective effect of the KIR2DS1 gene in atopic dermatitis. Gene 527:594-600

Norman PJ, Carrington CV, Byng M et al (2002) Natural killer cell immunoglobulin-like receptor (KIR) locus profiles in African and South Asian populations. Genes Immun 3:86-95

Nowak I, Majorczyk E, Ploski R et al (2011) Lack of KIR2DL4 gene in a fertile Caucasian woman. Tissue Antigens 78:115-119

Ozturk OG, Polat G, Atik U (2012) Diversity of killer cell immunoglobulin-like receptor genes in Southern Turkey. Mol Biol Rep 39:1989-1995

Pyo CW, Guethlein LA, Vu Q et al (2010) Different patterns of evolution in the centromeric and telomeric regions of group A and B haplotypes of the human killer cell Ig-like receptor locus. PLoS ONE 5:e15115

Pyo CW, Wang R, Vu Q et al (2013) Recombinant structures expand and contract inter and intragenic diversification at the KIR locus. BMC Genom 14:89

Rajagopalan S, Long EO (2012) KIR2DL4 (CD158d): an activation receptor for HLA-G. Front Immunol 3:258

Shaw J, Kollnberger S (2012) New perspectives on the ligands and function of the killer cell immunoglobulin-like receptor KIR3DL2 in health and disease. Front Immunol 3:339

Sivori S, Falco M, Carlomagno S et al (2010) A novel KIR-associated function: evidence that CpG DNA uptake and shuttling to early endosomes is mediated by KIR3DL2. Blood 116:1637-1647

Sun JY, Gaidulis L, Miller MM et al (2004) Development of a multiplex PCR-SSP method for Killer-cell immunoglobulin-like receptor genotyping. Tissue Antigens 64:462-468

Taniguchi M, Kawabata M (2009) KIR3DL1/S1 genotypes and KIR2DS4 allelic variants in the AB KIR genotypes are associated with Plasmodium-positive individuals in malaria infection. Immunogenetics 61:717-730

Traherne JA, Martin M, Ward R et al (2010) Mechanisms of copy number variation and hybrid gene formation in the KIR immune gene complex. Hum Mol Genet 19:737-751

Velickovic M, Velickovic Z, Dunckley H (2006) Diversity of killer cell immunoglobulin-like receptor genes in Pacific Islands populations. Immunogenetics 58:523-532

Vilches C, Castano J, Gomez-Lozano N et al (2007) Facilitation of KIR genotyping by a PCR-SSP method that amplifies short DNA fragments. Tissue Antigens 70:415-422

Wong-Baeza I, Ridley A, Shaw J et al (2013) KIR3DL2 binds to HLA-B27 dimers and free $\mathrm{H}$ chains more strongly than other HLA class I and promotes the expansion of T cells in ankylosing spondylitis. J Immunol 190:3216-3224

Yan WH, Lin A, Chen BG et al (2007) Possible roles of KIR2DL4 expression on uNK cells in human pregnancy. Am J Reprod Immunol 57:233-242 